\title{
ERS and tobacco harm reduction
}

\section{CrossMark}

\author{
Charlotta Pisinger ${ }^{1}$, Elif Dagli ${ }^{2}$, Filippos T. Filippidis $\mathbb{1}^{3}$, Linnea Hedman ${ }^{4}$, \\ Christer Janson ${ }^{5}{ }^{5}$, Stelios Loukides ${ }^{6}$, Sofia Ravara ${ }^{7}$, Isabel Saraiva ${ }^{8}$ and \\ Jørgen Vestbo ${ }^{9}$, the ERS Tobacco Control Committee, on behalf of the ERS
}

\begin{abstract}
Affiliations: 'University of Copenhagen and Bispebjerg-Frederiksberg Hospitals, Copenhagen, Denmark. ${ }^{2}$ Marmara University, Istanbul, Turkey. ${ }^{3}$ Dept of Primary Care and Public Health, Imperial College, London, UK. ${ }^{4}$ Dept of Sustainable Health, The OLIN Unit, Umeå University, Umeå, Sweden. ${ }^{5}$ Uppsala University, Uppsala, Sweden. ${ }^{6}$ National and Kapodistrian University of Athens, Athens, Greece. ${ }^{7} \mathrm{CICS}-\mathrm{UBI}$ - Health Sciences Research Centre, University of Beira Interior, Covilhã, Portugal and NOVA National School of Public Health, Public Health Research Centre, Universidade NOVA de Lisboa, Lisbon, Portugal. ${ }^{8}$ European Lung Foundation, Sheffield, UK. ${ }^{9}$ University of Manchester and the Manchester University NHS Foundation Trust, Manchester, UK.

Correspondence: Jørgen Vestbo, 2nd Floor, ERC Building, Wythenshawe Hospital, Southmoor Road, Manchester, M23 9LT, UK. E-mail: jorgen.vestbodmanchester.ac.uk
\end{abstract}

@ERSpublications

ERS supports the World Health Organization's Framework Convention on Tobacco Control, which also provides regulation to novel products, and cannot recommend tobacco harm reduction as a population-based strategy http://bit.ly/2rxTZ5b

Cite this article as: Pisinger C, Dagli E, Filippidis FT, et al. ERS and tobacco harm reduction. Eur Respir J 2019; 54: 1902009 [https://doi.org/10.1183/13993003.02009-2019].

Medical experts and federal health officials in USA have recently warned the public from using e-cigarettes, as the number of people with a severe lung illness rose to over 1600 cases, 34 of these fatal. An illustrative case is reported in the European Respiratory Journal [1]. Health officials state that "vaping is a probable potential cause" but no firm conclusions can yet be drawn. In this light it is interesting to discuss the concept of tobacco harm reduction. The European Respiratory Society (ERS) Advocacy Council's Tobacco Control Committee has recently launched an ERS position paper on this topic [2]. From this paper we would like to draw attention to some of the major issues of harm reduction.

A harm reduction strategy for smokers includes recommending the use of alternative nicotine delivery products such as e-cigarettes, smokeless tobacco or new heated tobacco products to smokers instead of conventional cigarettes, thus replacing a very harmful product with a less, but still harmful, product. The concept is intuitive and therefore very tempting for smokers, health professionals and politicians. Unfortunately, it is much more complex.

The ERS statement on harm reduction presents seven arguments, based on a review of the evidence, for why a harm reduction strategy should not be used as a population-based strategy in tobacco control.

Argument 1: The tobacco harm reduction strategy is based on incorrect claims that smokers cannot or will not quit smoking. The majority of smokers want to quit $[3,4]$ and a high proportion dislike being nicotine dependent [5]. Smokers today smoke fewer cigarettes daily, are more motivated to quit and report being less tobacco dependent than previously [6]. Evidence-based tobacco dependence treatment exists and is safe and effective [7].

This article has been revised according to the correction published in the January 2020 issue of the European Respiratory Journal.

Received: 12 Oct 2019 | Accepted: 14 Oct 2019

Copyright $\odot$ ERS 2019 
Argument 2: The tobacco harm reduction strategy is based on undocumented assumptions that alternative nicotine delivery products are highly effective as a smoking cessation aid. No "harm reduction" products have been approved for smoking cessation. There is lack of evidence to support that alternative nicotine delivery products are effective smoking cessation tools. One randomised controlled trial on smoking cessation found that e-cigarettes were twice as effective as nicotine replacement therapy after 1 year, when combined with intensive smoking cessation counselling. However, $80 \%$ of former smokers continued to use e-cigarettes after quitting conventional cigarettes and thus remained nicotine dependent [8]. On the other hand, 14 out of 15 longitudinal real-life studies showed that use of e-cigarettes significantly undermined abstinence [9]. Studies on smokeless tobacco as a smoking cessation tool have shown no effect $[10,11]$.

Argument 3: The tobacco harm reduction strategy is based on incorrect assumptions that smokers will replace conventional cigarettes with alternative nicotine delivery products. The majority of e-cigarette users (typically $60-80 \%$ ) continue to smoke $[12,13]$ and there seems to be no significant reduction in their consumption of conventional cigarettes [14]. Dual use is also very frequent in smokeless tobacco users [13]. For dual users there is no health benefit.

Argument 4: The tobacco harm reduction strategy is based on undocumented assumptions that alternative nicotine delivery products are generally harmless. However, there is no evidence that alternative nicotine delivery products are safe: on the contrary. Almost all independent studies indicate potential harm [15, 16]. The uncertainty seems to be around the degree of harm rather than the presence of harm related to these products, but we have no evidence on the long-term health effects of using e-cigarettes. E-cigarette aerosols can induce acute endothelial cell dysfunction and formation of reactive oxidative stress. Animal studies have shown numerous harmful effects [17-19]. Human experiments have shown airway obstruction and dysregulation in normal human lung homeostasis after short-term inhalation [20]. In addition, there is moderate evidence from population-based studies for increased cough and wheeze in adolescents and an increase in asthma exacerbations [14], even when only exposed to second-hand vapour from e-cigarettes. Smokeless tobacco is responsible for a large number of cancer deaths worldwide [21], while the evidence regarding the risk of cancer due to use of Swedish moist snuff/snus is inconclusive. We have very little knowledge of the health effects of heated tobacco devices. Animal data showed pulmonary inflammation and human data showed no improvement of lung function after switching from combustible to heated tobacco [22]. Independent researchers found that heated tobacco products have the potential to initiate changes in the airways related to chronic lung disease [18].

Argument 5: Alternative nicotine delivery products can have a negative impact on public health even if "stick-by-stick" they turn out to be less harmful than conventional cigarettes. When evaluating the pros and cons of alternative nicotine delivery products we must consider their impact on the whole population, not only on the smokers, who are a minority. From a public health point of view, these products may have an unfavourable net effect, especially because of increasing uptake by never-smokers. E-cigarettes with candy or fruit flavours strongly appeal to children and adolescents [23]. Some parts of the world have seen a significant spread of e-cigarettes amongst youth and young adults; epidemic-level rises in youth e-cigarette use are seen in both the USA and Europe [24, 25], and, at the time of writing, a ban on flavoured e-cigarettes has been suggested in the USA. A study in the general population showed that among e-cigarette users, those (re)starting smoking after using e-cigarettes outnumbered those who stopped smoking after using e-cigarettes. Furthermore, there is substantial evidence that adolescents' e-cigarette use increases their risk of smoking initiation of conventional cigarettes [14, 26]. Use of smokeless tobacco seems, like e-cigarette use, to increase the likelihood of smoking initiation.

Argument 6: Smokers see alternative nicotine delivery products as a viable alternative to the use of evidence-based smoking cessation services and smoking cessation pharmacotherapy. Effective evidence-based smoking cessation medication and services exist and are effective [6]. A decrease in use of smoking cessation services and medically tested pharmacotherapy has been observed in parallel with an increase in the use of e-cigarettes, indicating that alternative nicotine-containing products may be replacing evidence-based, effective smoking cessation tools [27].

Argument 7: The tobacco harm reduction strategy is based on incorrect claims that we cannot curb the tobacco epidemic. Many effective strategies exist to reduce smoking at a population level [2, 28]. The decline of smoking due to tobacco control measures is one of public health's greatest successes [29]. Countries with strong tobacco control have experienced impressive and rapid declines in smoking prevalence. We know what works. We need brave leaders to implement evidence-based effective tobacco control measures.

It must be acknowledged that many health professionals, tobacco control professionals and decision-makers who recommend the harm reduction strategy have very good intentions. They focus on 
the smokers and see harm reduction as a pragmatic way of reducing the devastating health effects of the tobacco epidemic. However, good intentions must always be supported by strong evidence before large-scale implementation. Evidence on the safety and the effectiveness of alternative nicotine delivery products as a smoking cessation tool is still lacking, while use of nicotine-containing products is spreading to non-smokers, which is most alarming. Harm reduction in tobacco control should be reserved for a minority of high-risk smokers; it is not a population-based strategy.

Another fact that cannot be ignored is that alternative nicotine delivery products are primarily manufactured by the tobacco industry, and the tobacco industry has a strong economic interest in spreading these products to as many individuals as possible: smokers as well as non-smokers. The tobacco industry has manufactured so called "safer" tobacco products (i.e. filter, light, low tar cigarettes) since the 1950s, and none of them have improved smokers' health. Alternative nicotine delivery products are the tobacco industry's adaptation to declining tobacco consumption and acceptability of smoking, and increased regulation of cigarettes.

When a smoker quits completely (but not partially) he or she will experience many health benefits, as there is no exposure to harmful substances any longer. Smokers who switch to alternative products will still have a long-term exposure to toxic and carcinogenic substances. Although reduced, this continued exposure to toxicants is a bad alternative to quitting smoking.

\section{What does ERS recommend?}

The tobacco harm reduction strategy is based on well-meaning but incorrect or undocumented claims or assumptions. 40 countries have already banned e-cigarettes and/or nicotine e-liquid.

The human lungs are created to breathe clean air, not "reduced levels of toxins and carcinogens", and the human body is not meant to be dependent on addictive drugs. ERS cannot recommend any product that is damaging to the lungs and human health. Therefore, ERS strongly supports implementation of World Health Organization's Framework Convention on Tobacco Control, which also provides regulation to novel products, and cannot recommend tobacco harm reduction as a population-based strategy [30].

Acknowledgements: J. Vestbo is supported by the NIHR Manchester BRC.

Conflict of interest: C. Pisinger has nothing to disclose. E. Dagli has nothing to disclose. F.T. Filippidis has nothing to disclose. L. Hedman has nothing to disclose. C. Janson has nothing to disclose. S. Loukides has nothing to disclose. S. Ravara has nothing to disclose. I. Saraiva has nothing to disclose. J. Vestbo reports fees for consultancy and presentations from AstraZeneca, Boehringer Ingelheim, Chiesi, GSK and Novartis; a family member is an employee of Chiesi

\section{References}

1 Fels Elliott DR, Shah R, Hess CA, et al. Giant cell interstitial pneumonia secondary to cobalt exposure from e-cigarette use. Eur Respir J 2019; 54: 1901922.

2 The ERS Tobacco Control Committee. ERS Position Paper on Tobacco Harm Reduction. www.ersnet.org/ advocacy/eu-affairs/ers-position-paper-on-tobacco-harm-reduction-2019. May 2019. Date last accessed: 28 September 2019.

3 Drope J, Schluger N. The Tobacco Atlas. 6th Edn. Georgia, American Cancer Society, 2018. www.cancer.org/ latest-news/twelve-key-findings-from-the-new-edition-of-the-tobacco-atlas.html. Date last accessed: 24 September 2019.

4 Thyrian JR, Panagiotakos DB, Polychronopoulos E, et al. The relationship between smokers' motivation to quit and intensity of tobacco control at the population level: a comparison of five European countries. BMC Public Health 2008; 8: 2 .

5 Orleans CT, Schoenbach VJ, Salmon MA, et al. A survey of smoking and quitting patterns among black Americans. Am J Public Health 1989; 79: 176-181.

6 Feliu A, Fernandez E, Martinez C, et al. Are smokers "hardening" or rather "softening"? An ecological and multilevel analysis across 28 European Union countries. Eur Respir J 2019; 541900596.

7 Cahill K, Stevens S, Perera R, et al. Pharmacological interventions for smoking cessation: an overview and network meta-analysis. Cochrane Database Syst Rev 2013; 5: CD009329.

8 Hajek P, Phillips-Waller A, Przulj D, et al. A randomized trial of e-cigarettes versus nicotine-replacement therapy. N Engl J Med 2019; 380: 629-637.

9 Kalkhoran S, Glantz SA. E-cigarettes and smoking cessation in real-world and clinical settings: a systematic review and meta-analysis. Lancet Respir Med 2016; 4: 116-128.

10 Tonnesen P, Mikkelsen K, Bremann L. Smoking cessation with smokeless tobacco and group therapy: an open, randomized, controlled trial. Nicotine Tob Res 2008; 10: 1365-1372.

11 Hatsukami DK, Severson H, Anderson A, et al. Randomised clinical trial of snus versus medicinal nicotine among smokers interested in product switching. Tob Control 2016; 25: 267-274.

12 Hedman L, Backman H, Stridsman C, et al. Association of electronic cigarette use with smoking habits, demographic factors, and respiratory symptoms. JAMA Netw Open 2018; 1: e180789.

13 Sung HY, Wang Y, Yao T, et al. Polytobacco use and nicotine dependence symptoms among US adults, 2012 2014. Nicotine Tob Res 2018; 20: Suppl. 1, S88-S98. 
14 Manzoli L, Flacco ME, Fiore M, et al. Electronic cigarettes efficacy and safety at 12 months: cohort study. PLoS One 2015; 10: e0129443.

15 National Academies of Sciences, Engineering, and Medicine; Health and Medicine Division; Board on Population Health and Public Health Practice; Committee on the Review of the Health Effects of Electronic Nicotine Delivery Systems. Stratton K, Kwan L, Eaton D, eds. Public Health Consequences of E-Cigarettes. Washington, National Academies Press (US), 2018.

16 Kennedy CD, van Schalkwyk MCI, McKee M, et al. The cardiovascular effects of electronic cigarettes: a systematic review of experimental studies. Prev Med 2019; 127: 105770.

17 Chen L, Ge Q, Tjin G, et al. Effects of cigarette smoke extract on human airway smooth muscle cells in COPD. Eur Respir J 2014; 44: 634-646.

18 Sohal S, Eapen M, Naidu V, et al. IQOS exposure impairs human airway cell homeostasis: direct comparison with traditional cigarette and e-cigarette. ERJ Open Res 2019; 5: 00159-2018.

19 Garcia-Arcos I, Geraghty P, Baumlin N, et al. Chronic electronic cigarette exposure in mice induces features of COPD in a nicotine-dependent manner. Thorax 2016; 71: 1119-1129.

20 Staudt MR, Salit J, Kaner RJ, et al. Altered lung biology of healthy never smokers following acute inhalation of E-cigarettes. Respir Res 2018; 19: 78.

21 Sinha DN, Suliankatchi RA, Gupta PC, et al. Global burden of all-cause and cause-specific mortality due to smokeless tobacco use: systematic review and meta-analysis. Tob Control 2018; 27: 35-42.

22 Glantz SA. PMI's own in vivo clinical data on biomarkers of potential harm in Americans show that IQOS is not detectably different from conventional cigarettes. Tob Control 2018; 27: Suppl. 1, S9-S12.

23 Dutra LM, Glantz SA. E-cigarettes and national adolescent cigarette use: 2004-2014. Pediatrics 2017; 139: e20162450.

24 Dai H, Leventhal AM. Prevalence of e-cigarette use among adults in the United States, 2014-2018. JAMA 2019; in press [https://doi.org/10.1001/jama.2019.15331].

25 Filippidis FT, Laverty AA, Gerovasili V, et al. Two-year trends and predictors of e-cigarette use in 27 European Union member states. Tob Control 2017; 26: 98-104.

26 Soneji S, Barrington-Trimis JL, Wills TA, et al. Association between initial use of e-cigarettes and subsequent cigarette smoking among adolescents and young adults: a systematic review and meta-analysis. JAMA Pediatr 2017; 171: 788-797.

27 Filippidis FT, Laverty AA, Mons U, et al. Changes in smoking cessation assistance in the European Union between 2012 and 2017: pharmacotherapy versus counselling versus e-cigarettes. Tob Control 2019; 28: 95-100.

28 World Health Organization. WHO Framework Convention on Tobacco Control. www.who.int/fctc/en. Date last accessed: 24 September 2019.

292014 Surgeon General's Report: The Health Consequences of Smoking - 50 Years of Progress. Rockville, US Department of Health, Human Services, 2014.

30 World Health Organization. The Convention Secretariat calls Parties to remain vigilant towards novel and emerging nicotine and tobacco products. Geneva, WHO, 2019. www.who.int/fctc/mediacentre/news/2019/remain-vigilant-towardsnovel-new-nicotine-tobacco-products/en/?utm_source=BenchmarkEmail\&utm_campaign=Special_edition_September_ 2019_FINAL\&utm_medium=email. Date last accessed: 24 September 2019. 